\title{
PROPER EXPRESSION FOR THE AMOUNT OF 11 WITH THE FRACTIONAL PART OF A YEAR'S INTEREST.
}

\section{To the Editor of the Assurance Magazine.}

SIR,-In your last Number you inserted a communication from me, "On the Period intervening between the date of Death and Payment of the Sum assured." In that communication, $(1-i \mathrm{~A})$ was deduced as the present value of $£ 1$ due from the beginning of the year of death, and therefore of $£ 1$ with half a year's interest midway in the year of death, or with a full year's interest at the end of year of death. Consequently, on the recognised assumption that lives on an average die midway in the year of death, $\frac{1-i \text { A }}{1+\frac{i}{2}}$ would represent the present value of $f 1$ due from the time

of death. Finding upon trial that the values, when thus obtained to three places of decimals, were concurrent with those set forth by Mr. Sang in his tables, I was induced to think, in the absence of any explanation on his own part, that he must also have been led to the requisite formula already deseribed. It appears, however, from a statement by Mr. Chisholm (Assurance Magazine, No. VIII.), and, more recently, from a note (alluding to my commumication) appended by Mr. W. T. Thoinson to the introduction of his own laborions actuarial tables, that Mr. Sang really employed $\sqrt{1+i}$ as the amount of 11 with half a year's interest, instead of $1+\frac{i}{2}$, as

\section{I had supposed.*}

It is obviously to be regretted that Mr. Sang should have infected his tables with this aneient error of D'Alembert, the adoption of which by Mr. Smart in his otherwise valuable interest tables (2nd edition, 1726) had already been animadverted on (vide Milne, pp. 25 and 693); becanse if $\sqrt{1+i}$ be taken as the amount of $£ 1$ with half a year's interest, we must also take $(1+i)^{\frac{1}{n}}$ as that of $£ 1$ with $\frac{1}{n}$ th of a year's interest, and therefore $\left[(1+i)^{\frac{1}{n}}\right]^{\mathrm{n}}$ as the amount of $£ 1$ at interest for a year, when interest is payable $\frac{1}{n}$ thly; or, in other words, the obvious mal-interpretation must be adopted, that interest payable half yearly, quarterly, monthly, or even momently, is not to be made more productive than interest

* Mr. Thomson says- "Sang, in all his assurance ealculations, considered the rate of interest of half a year, not as Mr. Farren says, $\frac{i}{2}$ or $\cdot 015$, but $\sqrt{1+i}$ or $\sqrt{1 \cdot 03 . "}$

Whatever may have been Mr. Sang's practice in Scotland, to English readers at least half a year's interest on $£ 1000$ at 3 per cent. would imply $£ 15$, and not $£ 14$. 17 s. $9 \frac{7}{4} d$., in consideration of the square root; especially when that square root as of 1.03 is itself really incommensurable. Neither can such a procedure have reference to the time of death ; for a peried described as the square root of the year of death would seem more allied to sound than sense.

It is right, however, to state that Mr. Thomson has fairly limited himself to indicating what Mr. Sang's own practice was, without enrolling himself among his disciples. 
payable yearly, for $\left[(1+i)^{\frac{1}{n}}\right]^{n}=(1+i)$ equally for all values of $n$.

In my former communication, then, I was content to allow Mr. Sang the credit of having avoided this error; but, after the express testimony of his friend Mr. Thomson, we are forced upon the consideration that Mr. Sang's use of the facility of dividing the yearly logarithm, coupled with his own silence on the subject, are not circumstances wholly beyond reproach, when viewed in connection with the construction of numerical tables upon which others may have to depend.

London, May 1853.

EDWIN JAS. FARREN.

\section{ON THE SAME SUBJECT AS THE FOREGOING.}

To the Editor of the Assurance Magazine.

$\mathrm{SIR},-$ Observing in No. XI. of your Magazine a paper by Mr. E. J. Farren, containing some very neat and concise remarks "On the Period intervening between the date of Death and Payment of Sum assured," I feel called upon to say a few words on the subject, more particularly with reference to the mode in which it was treated by Mr. Sang, in the hope that you will give them a place in your pages.

I have since minutely examined the construction of Mr. Sang's Assurance Table, and am nable to discover what precise meaning he attached to the element introduced by him $(\sqrt{1003})$ to adjust the values for sums payable at the instant of death. If it was intended to express the amount of E1 with six months' interest at 3 per cent. per annum, he must have assumed the conversion of interest to be twice in the year; for a somewhat smaller rate of interest than 3 per cent. per annum, if improved half yearly, will be sufficient to bring up the quantity $\sqrt{1.03}$ to the desired amount, 1.03 , at the end of one year. In short, the half yearly rate of interest is $\sqrt{1} \cdot 03-1$, or $\cdot 014889$. But I notice that Mr. Sang, in the illustration of his published tables, in conformity with the practice and principles of previous computers, assumes the interest to be accumulated yearly, in which case the amount of $\mathfrak{f 1}$ with six months' interest must be held to be $1 \cdot 015$, and not $\sqrt{1 \cdot 03}$.

This will be more evident on examination of his formula representing the value of an assurance of $\mathfrak{E 1}$ payable at the instant of death, viz -

which is equal to

$$
\frac{v^{\frac{1}{2}} d_{x}+v^{1+\frac{1}{2}} d_{x+1}+v^{2+\frac{1}{2}} d_{x+2}}{l_{x}}, \& \mathrm{c},
$$

$$
\frac{1}{\sqrt{1+i}} \times\left(\frac{v d_{x}+v^{2} d_{x+1}+v^{3} d_{x+2}}{l_{x}}, \text {, } \mathrm{cc}\right)
$$

In this formula, the quantity enclosed within ( ), being the ordinary expression for the value of an assurance payable six months after death (see Jones, vol. i., page 155), most clearly assumes the interest to be capitalized only once a year. Hence the other element in that expression, or $\frac{1}{\sqrt{1 \cdot 03}}$ the present value of $£ 1$ payable six months hence, at *014889 per cent. 